\title{
A RARE CASE OF OVARIAN HYPERSTIMULATION AFTER CLOMIPHENE CITRATE RESULTING IN TORSION AND RUPTURE
}

\author{
Rukshana ${ }^{1}$, S. Suganya Devi², Syamala ${ }^{3}$, Usha Rani ${ }^{4}$
}

\section{HOW TO CITE THIS ARTICLE:}

Rukshana, S. Suganya Devi, Syamala, Usha Rani. "A Rare Case of Ovarian Hyperstimulation after Clomiphene Citrate Resulting in Torsion and Rupture". Journal of Evolution of Medical and Dental Sciences 2014; Vol. 3, Issue 09, March 3; Page: 2373-2377, DOI: 10.14260/jemds/2014/2147

ABSTRACT: Ovarian hyperstimulation is a dreaded complication of ovarian stimulation protocols in infertility and is known to complicate about 5-10\% of ART cycles. Following gonadotropin therapy, OHSS (Ovarian hyperstimulation) usually develops several days after assisted ovulation or oocyte retrieval. But it is quite rare with clomiphene therapy which in general causes unifollicular development. Here we are presenting an interesting case of ovarian hyperstimulation which presented with rupture and massive hemoperitoneum resulting in hemodynamic instability. It is all the more rare because the agent used for ovarian stimulation was clomiphene citrate at its minimum dose.

KEYWORDS: Ovarian hyperstimulation, clomiphene citrate, Ovarian torsion.

INTRODUCTION: Ovarian hyperstimulation syndrome (OHSS) is an iatrogenic systemic disease ${ }^{1}$. The pathophysiology of OHSS is characterised by increased capillary permeability, leading to leakage of fluid from the vascular compartment to the extra vascular space with third space fluid accumulation and intravascular volume depletion. This may cause hypoalbuminaemia, hemoconcentration, electrolyte imbalance, decreased renal perfusion and oliguria, ascites, pleural/pericardial effusions, which may precipitate significant morbidity and mortality from thrombosis, renal, liver and respiratory failure (ARDS). Ovarian enlargement may also create risk of torsion and cyst rupture. Ovarian torsion causes acute abdominal pain with an incidence of 1 in 5000 stimulation cycles. Torsion has been reported frequently in association with OHSS or pregnancy. ${ }^{2}$ Ovarian bleeding may be caused by ovarian rupture which may have been precipitated by pressure or bimanual examination. This manifests with signs of acute hemorrhage and hemodynamic instability (hypotension, nausea, sudden drop in hematocrit).

The occurrence of OHSS is dependent on the administration of human chorionic gonadotropin (hCG). The condition is self-limiting and usually resolves spontaneously within several days, but may persist for longer duration, particularly in treatment cycles where conception occurs. It represents a supraphysiological response to ovarian stimulation, and is usually associated with the administration of exogenous gonadotropins, and very rarely with clomiphene citrate. Mild forms of the disease are common, and affect up to $33 \%$ of IVF cycles, while moderate and severe forms complicate $3-8 \%$ of cycles $^{3}$. Incidence with clomiphene citrate is yet to be evaluated.

CASE REPORT: A 22 year old nulliparous lady with primary subfertility, married since 3 years presented with severe pain abdomen and multiple episodes of vomiting to the emergency department. She gave history of being prescribed clomiphene citrate $(50 \mathrm{mg}$ once a day for 5 daysD2 to D6) following her last menstrual cycle. She had history of diagnostic hysterolaproscopy with left tubal canalization done. On admission patient appeared pale with abdominal distension and 
diffuse tenderness. Lab investigations, hemoglobin on admission was $8.3 \mathrm{~g} \%$, which further dropped to $6.7 \mathrm{~g} \%$ on the next day. Beta HCG was $376 \mathrm{mIU} / \mathrm{ml}$. One unit packed cell was transfused. USG pelvis done on admission had features of OHSS.A provisional diagnosis of ovarian hyperstimulation was made and conservative management was planned. 24 hours after admission, patient appeared to be worsening with further drop of hemoglobin to 6.2 $\mathrm{g} \%$, and increasing Abdominal distension and hence paracentesis was done. 20cc of frank blood was aspirated. In view of hemoperitoneum with impending hypotension patient was taken up for emergency laparotomy.

Intraoperatively massive hemoperitoneum was noted. $800 \mathrm{gm}$ of clots and $1800 \mathrm{ml}$ of hemoperitoneum was present. Both ovaries had multiple cysts with rupture and active bleeding on the surface and torsion on their respective ovarian pedicles. Hemostasis was achieved on the right ovary but left ovary could not be salvaged, hence left oophorectomy done. Patient was then followed up with serial Beta HCG once in 48 hours, which was found to be doubling. Ultrasound done after 1 week showed intrauterine gestational sac with DCDA twins.

Patient was asked to come for follow up on regular basis for antenatal checkup. First twin showed features of IUGR which finally resulted in intra uterine fetal demise at 30 weeks. In view of fetal distress in twin 2, emergency LSCS was done.

Fetus A-IUD delivered by cephalic presentation, weight of the baby 560 grams, placenta weight 450 grams.

Fetus B transverse lie, delivered by assisted breech delivery, baby Boy, 1.4kg, APGAR- 3/10, $8 / 10$.

DISCUSSION: The clinical presentation in the case reported here constitutes a diagnostic dilemma as a number of gynaecological conditions could present the same way, such as ruptured ectopic pregnancy, rupture of hemorrhagic ovarian cyst. OHSS in pregnancy is a risk factor for developing torsion, which should increase the index of suspicion, and thereby facilitate early diagnosis and treatment ${ }^{2}$. Cases of adnexal torsion have been reported in association with OHSS, 4-7 but there is no information on the clinical picture or the incidence of twisted adnexa in pregnant patients with OHSS. The accuracy of a preoperative diagnosis of adnexal torsion during pregnancy is only $70 \% .{ }^{5}$ This remains a diagnostic challenge for gynaecologist's It is therefore imperative to consider the possibility of torsion in women with OHSS.

Clomiphene citrate is the most commonly prescribed drug for ovulation induction and accounts for two thirds of all infertility drug uses. It has been reported that about $90 \%$ of infertile women in our environment have used clomiphene, either self-administered or prescribed by medical personnel, and more often without preliminary assessment of anovulation.Following the introduction of clomiphene citrate, the reported incidence of mild and moderate OHSS was $13.5 \%$ and $8 \%$, respectively. Only rarely is clomiphene citrate treatment associated with the severe form of the syndrome.Severity of OHSS has been reported to be further aggravated with pregnancy and termination of pregnancy may be opted as a safety measure. Though most common gynaecological conditions such as ectopic pregnancy and ovarian torsion tend to be impossible to eliminate spontaneously and may require surgery immediately, management of OHSS is supportive while awaiting spontaneous resolution. Ascites could be tapped through paracentesis, when symptoms of respiratory distress are present. Surgical management aggravates electrolyte imbalance even more and also increases morbidity. In fact, surgery is necessary only in extreme cases, such as in the case of 
ovarian torsion, a ruptured cyst, or an internal hemorrhage. Laparotomy is life saving and recommended in case of torsion and also intraperitoneal hemorrhage. In our case acute intraabdominal bleeding and hemodynamic instability convinced us to proceed with emergency laparotomy.

This case demonstrates the morbidity that can result from clomiphene administration, even with appropriate indications. Preventing OHSS is still a challenge. ${ }^{8}$ Special attention must be given to primary prevention by identifying the "at risk" patients. ${ }^{9-11}$ Secondary risk factors such as elevated serum estradiol $\left(E_{2}\right)$ levels during ovarian stimulation and/or on the day of hCG administration constitute important risk factors for developing OHSS. High $\mathrm{E}_{2}$ levels are often associated with a large cohort of recruited follicles that may be responsive to hCG administration.

\begin{tabular}{|l|l|}
\hline Primary risk factors $^{8}$ & \multicolumn{1}{|c|}{ Secondary risk factors } \\
\hline Young age & High number of medium/large follicles \\
\hline High basal AMH & High or rapidly rising E2 levels and high number of follicles \\
\hline Previous OHSS & Number of oocytes retrieved \\
\hline PCO like ovaries & Pregnancy, HCG administration \\
\hline
\end{tabular}

CONCLUSION: Clomiphene citrate although rarely associated with OHSS. This morbid condition should still be considered and problems secondary to it must be anticipated. Appropriate vigilance can prove to be lifesaving as shown in this case.

\section{REFERENCES:}

1. Ovarian Hyperstimulation Syndrome (OHSS) Diagnosis and Management. Institute of Obstetricians and Gynaecologists, Royal College of Physicians of Ireland and Directorate of Strategy and Clinical Programmes, Health Service Executive Version 1.0 April 2012 Guideline No. 9 Revision date: April 2014

2. Mashiach S, Bider D, Morano Goldenberg M en Ben Rafael Z. Adnexal torsion of hyperstimulated ovaries in pregnancies after gonadotropin therapy. FertilSteril 1990; 53: 76-80.

3. Delvigne A, Rozenberg S. Epidemiology and prevention of ovarian hyperstimulation syndrome (OHSS): a review. Human Reproduction Update 2002:8:559-77.

4. Schenker JG, Weinstein D. Ovarian hyperstimulation syndrome: a current survey. Fertil Steril 1978; 30:255.

5. Hibbard LT. Adnexal torsion. Am J Obstet Gynecol 1985; 152:456.

6. Hurwitz A, Milwidsky A, Yagel S, Adoni A. Early unwinding of torsion of an ovarian cyst as result of hyper- stimulation syndrome. Fertil Steril 1983; 40:393.

7. Chin NW, Friedman CI, Awadalla SG, Miller FA, Kim MH. Adnexal torsion as a complication of superovulation for ovum retrieval. Fertil Steril 1987; 48:149.

8. Mocanu E, Redmond ML, Hennelly B, Collins C, Harrison R. Odds of ovarian hyperstimulation syndrome (OHSS) - time for reassessment. Human Fertility (Camb). 2007; 10:175-81.

9. Lee TH, Liu CH, Huang CC, Wu YL, Shih YT, Ho HN, Yang YS, Lee MS. Serum anti-Müllerian hormone and estradiol levels as predictors of ovarian hyperstimulation syndrome in assisted reproduction technology cycles. Hum Reprod. 2008; 23: 160-167. [PubMed] 
10. Kwee J, Elting ME, Schats R, McDonnell J, Lambalk CB. Ovarian volume and antral follicle count for the prediction of low and hyper responders with in vitro fertilization. Reprod Biol Endocrinol. 2007; 5:9. doi: 10.1186/1477-7827-5-9. [PMC free article] [PubMed] [Cross Ref]

11. Papanikolaou EG, Pozzobon C, Kolibianakis EM, Camus M, Tournaye H, Fatemi HM, Van Steirteghem A, Devroey P. Incidence and prediction of ovarian hyperstimulation syndrome in women undergoing gonadotropin-releasing hormone antagonist in vitro fertilization cycles. Fertil Steril. 2006; 85:112-120. doi: 10.1016/j.fertnstert.2005.07.1292. [PubMed] [Cross Ref]

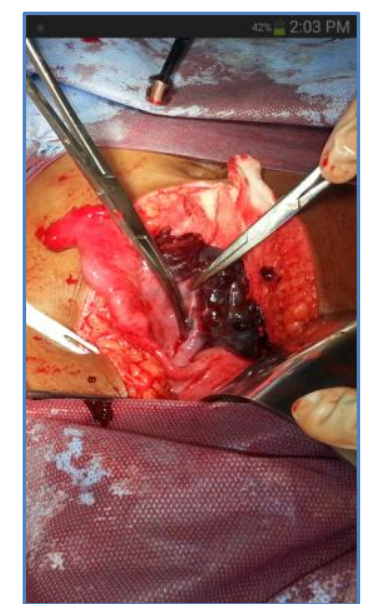

Left Oopherectomy done

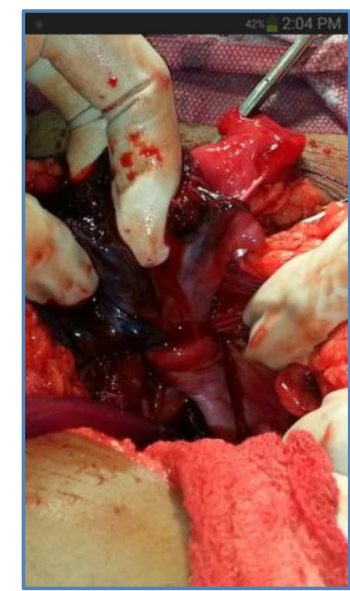

left ovary with torsion and rupture

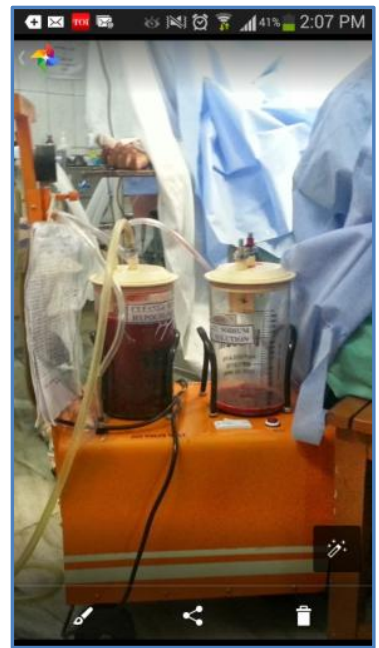

$1800 \mathrm{ml}$ of hemo peritoneum

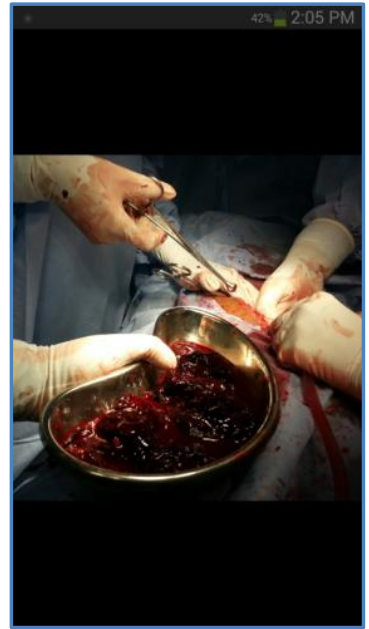

800 gms of clots were present 


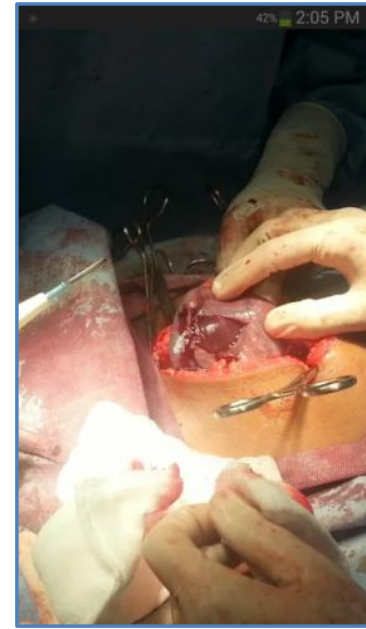

right ovary with multiple cyst with rupture and bleeding

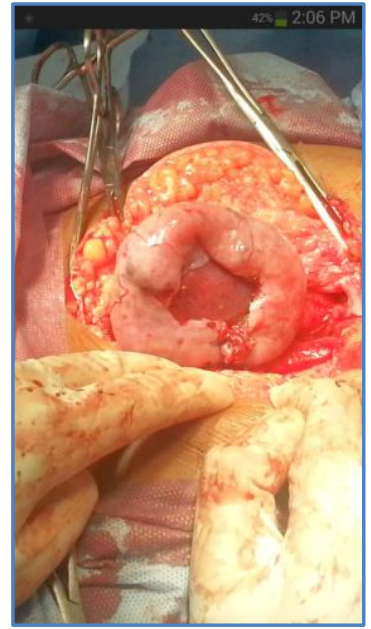

right ovary with multiple cyst after securing hemostasis

\section{AUTHORS:}

1. Rukshana

2. S. Suganya Devi

3. Syamala

4. Usha Rani

\section{PARTICULARS OF CONTRIBUTORS:}

1. Assistant Professor, Department of Obstetrics and Gynaecology, Sri Ramachandra University.

2. Post Graduate, Department of Obstetrics and Gynaecology, Sri Ramachandra University.

3. Associate Professor, Department of Obstetrics and Gynaecology, Sri Ramachandra University.
4. Professor, Department of Obstetrics and Gynaecology, Sri Ramachandra University

\section{NAME ADDRESS EMAIL ID OF THE} CORRESPONDING AUTHOR:

\section{Dr. S. Suganya Devi,}

$63 / 67,4^{\text {th }}$ Street Officers Colony,

Metha Nagar, Chennai - 600029 .

E-mail: suganya_arul@hotmail.com

Date of Submission: 11/02/2014.

Date of Peer Review: 12/02/2014.

Date of Acceptance: 19/02/2014.

Date of Publishing: 01/03/2014. 